\title{
Impact of African Weaver Ant Nests [Oecophylla longinoda Latreille (Hymenoptera: Formicidae)] on Mango [Mangifera indica L. (Sapindales: Anacardiaceae)] Leaves
}

\author{
1 - Université d'Abomey Calavi, Cotonou, République du Bénin \\ 2 - Université d'Agriculture de Kétou, Cotonou, République du Bénin \\ 3 - Aarhus University, Denmark \\ 4 - Biocontrol Unit for Africa, Cotonou, République du Bénin
}

FM ANATO ${ }^{1}$, A SINZOGAN ${ }^{1}$, A AdANDONON ${ }^{2}$, X HOUNLIdJ ${ }^{1}$, J OFFENBERG ${ }^{3}$, DK KOSSOU ${ }^{1}$, J-F VAYSSIÈreS ${ }^{4}$

\section{Article History}

Edited by

Gilberto M. M. Santos, UEFS, Brazil

Received 20 June 2014

Initial acceptance 21 August 2014

Final acceptance 04 September 2014

\section{Keywords}

weaver ants, leaf performance, ant nests, biocontrol, plant costs, Benin.

\section{Corresponding author}

Florence Mahouton Anato

Université d'Abomey Calavi, 07 BP 1130,

Cotonou, République du Bénin

E-Mail: anatoflorence@yahoo.fr

\begin{abstract}
Oecophylla ants are appreciated for their control of pests in plantation crops. However, the ants' nest building may have negative impacts on trees. In this study we tested the effect of ant densities and nest building on the leaf performance of mango trees. Trees were divided into three groups: trees without ants, trees with low and trees with high ant densities. Subsequently, the total number of leaves, the proportion of leaves used for nest construction, and tree growth was compared between these groups. The percentage of leaves used for nests was between 0.42-1.2\% (mean $=0.7 \% \pm 0.02$ ) and the total number of leaves and tree growth was not significantly different between trees with and without ants. Further, leaf performance was compared between shoots with and without ant nests and between leaves in or outside ant nests. The number of leaves and lost leaves per shoot, leaf size, leaf condition (withered), leaf longevity and hemipteran infection was compared between groups. In the dry season nest-shoots held more leaves than shoots without nests despite nest-shoots showed more lost leaves. Leaves in nests were smaller than other leaves, more likely to wither and more often infested with scales. However, smaller nest-leaf size was probably due to the ants' preference for young leaves and the higher incidence of withering resulting as leaves in nests cannot fall to the ground. In conclusion, the costs associated to ant nests were low and did not affect the overall number of leaves per tree nor tree growth.
\end{abstract}

\section{Introduction}

Among tropical fruits, mango (Mangifera indica L.) has the highest potential for food security (Vayssières et al., 2008) and incomes (Tinkeu et al., 2010) in West Africa. Costeffective, locally available and sustainable pest management options for this fruit are considered necessary to enhance its production, consumption and export. In Africa, Oecophylla longinoda Latreille has been detected as an effective plant protector (Way \& Khoo, 1992; Dwomoh et al., 2009; Olotu et al., 2013; Anato et al. unpublished data) and can increase fruit yields and/or fruit quality compared to conventional synthetic insecticides (Van Mele, 2008; Dwomoh et al., 2009; Anato et al., unpublished data).
The relationship, however, between the ants and their host plants involve negative as well as positive aspects, from a plant point of view. Ants are engaged in mutualistic trophobiotic interactions with plant sap sucking hemipterans and may in this way indirectly damage plants (Buckley, 1987; Van Mele et al., 2007). On the other hand, they also feed on various herbivorous arthropods and can in this way benefit host plants (Way, 1954; Hölldobler, 1983; Van Mele \& Cuc, 2003; Lim et al., 2008). Further, on the negative side, weaver ants weave leaves together (Crozier et al., 2010) and deposit territorial marking on leaves (Offenberg, 2007) which may reduce the efficiency of photosynthesis on their host plant. Also, when ants interlace leaves and turn them out of their original position, they can increase tension on the leaf petiole 
and potentially cause a premature detachment of the leaf from the shoot (Dillwith et al., 1991; Riedell \& Blackmer, 1999; Offenberg et al., 2006). Thus, Oecophylla nest building may result in indirect cost to the leaves used for their nest construction.

In Benin weaver ants are able to reduce fruit fly infestations in mango so efficiently that farmers' negative perceptions of the ants are changing toward a more positive attitude (Van Mele et al., 2007; Sinzogan et al., 2008; Van Mele et al., 2009). The ants are often integrated as a biocontrol component in IPMprograms. However, when promoting weaver ants, the scientific community is often facing questions from end users (farmers, extension officers) relating to the possible effect of the ants' nest building on the trees leaf performance. Some end users suspect that the presence of weaver ant nests (i) decreases the number of leaves on the trees and may have a negative impact on (ii) the size of leaves, (iii) their condition (more withering leaves), (iv) longevity and (v) on hemipteran infections. The effect of weaver ants (Oecophylla spp.) on such plant responses has not yet been tested on crop plants. The objective of this study was therefore to evaluate the effect of the density of $O$. longinoda on the host tree responses listed above.

\section{Materials and methods}

The study was conducted from September 2012 to September 2013 in N'dali in the Borgou area located between longitude $02^{\circ} 04^{\prime}-03^{\circ} 33^{\prime} \mathrm{E}$ and latitude $09^{\circ} 24^{\prime}-12^{\circ} 08^{\prime} \mathrm{N}$ which is the major mango production area in Benin (Vayssières et al., 2008). The mango orchard selected for the experiments had on average 100 trees ha-1 at $10 \mathrm{~m} \times 10 \mathrm{~m}$ spacing and were dominated by the variety "Gouverneur". All the trees were 15 years old and had similar size and appearance. The orchard was colonized by weaver ants 10 years ago and thus had trees with varying ant densities.

\section{The effect of ants on leaf numbers and tree growth}

Mango trees in the plantation were inspected and divided in two groups - trees with and without weaver ants. After that, ant densities on ant-trees were assessed using two different methods - a trail density estimate and a nest density estimate. In the first approach ant densities were estimated with the Forager Density Index (FDI) (Offenberg and Wiwatwitaya, 2010) which is based on the number of main trunks on a particular tree that is holding an ant trail (for more details see Offenberg \& Wiwatwitaya, 2010). With this approach the FDI was collected fortnightly (12 times) from September 2012 to February 2013. Based on the first survey, trees were divided into three groups: 1) trees without ants $(\mathrm{FDI}=0) ; 2$ ) trees with medium ant densities (FDI between $50-80 \%$ ) and 3 ) trees with high ant densities (FDI $>80 \%$ ). Twenty trees were then haphazardly selected from each group. In the second method the number of active ant nests in each tree was counted fortnightly (12 times) from April
2013 to September 2013. A nest was considered active if ants were defending it when shaken it with a pole. Based on the initial number of nests (found in the first survey) in each trees, trees were divided into three groups: 1) trees without ant nests, 2) trees with a medium nest density (from 20 to 40 nests), and 3) trees with a high nest density (more than 60 nests). In this design seven weaver ant colonies were chosen and two trees per nest density were selected haphazardly in each colony equaling 14 trees per group. In both methods, trees that were originally without ants were kept ant-free by preventing ant access using a sticky band (Oecotak 5; Oecos Ltd, U. K.) around the base of the tree trunks. As ant densities in ant trees may change over time the average density per tree was calculated for the whole period and based on this average trees were redistributed into the three different density groups before analyzing the effect of density on response variables.

In addition to registering the FDI and number of nests $(\mathrm{Nn})$ in each tree, the trees total number of leaves $(\mathrm{Nl})$ was also estimated fortnightly, and their diameter at breast height (dbh) measured. Diameter at breast height (dbh) was also taken on the main trunk at $1.30 \mathrm{~m}$ above the ground with ribbon "pi" (specific ribbon used by foresters to measure tree $\mathrm{dbh}$ ) of 1-cm precision. To estimate a trees' total number of leaves a modified version of Korine et al. (2000) method was used. Originally, Korine et al. (2000) categorized tree branches into main branches, secondary branches and small branches with leaves. The total number of main branches was counted for each tree and six branches were haphazardly selected. On these six main branches, all secondary branches were counted and one secondary branch haphazardly selected where all small branches were counted. The number of leaves was then assessed on 30 small branches, haphazardly selected from one secondary branch. Based on this, the average number of leaves per small branch was calculated. The average number of leaves on a tree was then calculated as: $\mathrm{Nl}=\mathrm{nal}{ }^{*} \mathrm{nsmb}^{*} \mathrm{nsb}^{*} \mathrm{nmb}$, where $\mathrm{Nl}$ is the number of leaves on the tree, nal is the average number of leaves per small branch, nsmb the number of small branches, nsb the number of secondary branches and nmb the number of main branches. We modified this method to adapt for the branching morphology of mango trees. As mango generally have less than 6 main branches but has secondary and tertiary branches, we changed the equation by introducing tertiary branches, to: $\mathrm{Nl}=$ nal*nsmb*nsb*ntb*nmb, where ntb is the number of tertiary branches. The total number of leaves on a tree was then compared to the number of leaves used for ant nest construction - the latter found by multiplying the number of nests on the tree with the average number of leaves used per nest (see below). The proportion of nest leaves to the total number of leaves was then calculated for each tree.

\section{Ant nests' effect on mango leaves and shoots}

Ten fortnightly surveys (five in the harmattan season [November to December 2012] and five in the rainy season 
[May-June 2013]), were done to compare the performance of leaves inside and outside ant nests. Fifteen trees ( 3 per survey) with ant nests were selected randomly in the orchard per season. On these trees all shoots with ant nests (nest shoots) were collected, and serving as control shoots, the nearest shoot to each nest shoot was also collected. Collected shoots were placed individually in plastic bags and frozen before examination. Leaves on nest shoots were categorized as either nest leaves if they were used for nest construction, or control leaves if they were not incorporated into an ant nest. On control shoots, all leaves were control leaves. On each shoot the following variables were registered / calculated: total number of leaves, percentage of leaves used for nest construction, the size of all leaves, each leafs' condition (green vs. withered yellow), percentage of lost leaves, and the percentage of leaves colonized by trophobiotic hemipterans. Leaf sizes were estimated using the method of Pandey and Singh (2011). Each leaf was placed on paper and its outline cut out and weighed on an electronic balance. The mass of the paper outline was then divided by the mass of a $1 \mathrm{~cm}^{2}$ piece of paper to provide an estimate of the leaf area. The number of lost leaves was registered by counting leaf scars left by lost leaves on the petioles.

\section{Data analysis}

The number of leaves and number of nests per tree, the number of leaves used for nest construction, the number of leaves per shoot and leaf areas were transformed with $\log 10[\mathrm{x}+1]$ to stabilize the variance and achieve normality of the data before analysis. A multivariate repeated measures analysis of variance was performed to test if time and ant density affected the total number of leaves on the trees and one way ANOVAs was used to test for the effect of ant density on the number of nests per tree, the number of leaves used for nest construction and the dbh. One way ANOVAs was also used to compare the total number of leaves per shoot and the leaf area of leaves between nest shoots and control shoots. As it was not possible to transform the percentage of leaves used for nest construction, lost leaves, withered leaves and leaves with scale insects, to normal distributions, these responses were tested with non-parametric Wilcoxon tests. All analyses were done with JMP 10.0.0.

A $\log 10(x+1)$ transformation was used on the number of nests and number of leaves used in nests constructions to stabilize variance and normalize the data (Dagnelie, 2003). As the percentage of leaves used for nest construction could not be transformed to a normal distribution, a non-parametric Wilcolxon test was performed.

\section{Results}

The effect of ant density in the trees showed the same trend on the response variables if initial densities or the average densities were used to categorize trees into the three different density categories. Thus, only the categorization based on the average densities was used in the presented results.

\section{The effect of ants on leaf numbers and tree growth}

Table 1 shows the mean number of nests per ant-tree in the different density groups and from the sampling of nests from shoots it was found that weaver ants used an average of $12.68 \pm$ $0.26 \mathrm{SE}$ leaves to construct their nests. Based on these measures it was found that the proportion of tree leaves used to construct nests was significantly different between trees with low and high trail densities $\left(\mathrm{F}_{1,478}=45.81 ; \mathrm{P}<0.0001\right)$, as well as between trees with low and high nest densities $\left(\mathrm{F}_{1,334}=473.80 ; \mathrm{P}<0.0001\right)$ (Table 1). Yet, the weaver ants used only on average $0.72 \pm 0.02 \mathrm{SE} \%$ $(0.42-1.20 \%)$ of the total number of mango leaves to construct their nests on the trees (Table 1). This proportion was too low to affect an overall effect on the amount of leaves on the trees as there was no significant difference between density groups on

Table 1. Statistics on the effect of ant density (Oecophylla longinoda) on the number of ant nests and leaves on mango trees. Numbers are mean values \pm SE per tree.

\begin{tabular}{cccc}
\hline & Number of nests & $\begin{array}{c}\text { Number of leaves used for nest } \\
\text { construction }\end{array}$ & $\begin{array}{c}\text { Percentage of leaves for nest } \\
\text { construction \% }\end{array}$ \\
\hline Trail density approach & $22.77 \pm 0.68$ & $288.77 \pm 8.61$ & $0.49 \pm 0.02$ \\
Low density & $35.31 \pm 1.77$ & $447.76 \pm 22.44$ & $0.77 \pm 0.05$ \\
High density & $\mathrm{F}_{(1,478)}=45.84 ;$ & $\mathrm{F}_{(1,478)}=45.84 ;$ & $\chi^{2}=27.65 ; \mathrm{Df}=1 ;$ \\
Statistics* & $\mathrm{P}<0.0001$ & & $\mathrm{P}<0.0001$ \\
Nest density approach & $28.05 \pm 0.73$ & $355.67 \pm 9.25$ & $0.42 \pm 0.01$ \\
Low nest & $62.82 \pm 1.47$ & $796.61 \pm 18.70$ & $1.20 \pm 0.04$ \\
High nest & $\mathrm{F}_{(1,334)}=473.79 ;$ & $\mathrm{F}_{(1,334)}=473.79 ;$ & $\chi^{2}=186.52 ; \mathrm{Df}=1 ; \mathrm{P}<0.0001$ \\
Statistics* & $\mathrm{P}<0.0001$ & &
\end{tabular}

* ANOVA/Wilcoxon Statistics 
the total number of leaves per tree even after excluding those leaves that were used in ant nests $\left(\mathrm{F}_{2,57}=1.38, \mathrm{P}=0.26\right.$ in the trail density approach; $\mathrm{F}_{2,39}=2.82, \mathrm{P}=0.08$ in the nest density approach) (Table 2 and Fig 1).

The dbh of the trees was also not affected by ant densities. Mean dbh was $80.04 \pm 5.54 \mathrm{SE}, 72.05 \pm 3.38 \mathrm{SE}$ and $73.94 \pm 3.93 \mathrm{SE} \mathrm{cm}$ for control trees without ants, trees with low trail densities and trees with high trail densities, respectively $\left(\mathrm{F}_{2,57}=0.92 ; \mathrm{P}=0.41\right)$. A similar trend was seen when trees were categorized according to nest densities. In this case mean dbh was $95.52 \pm 7.32 \mathrm{SE}, 105.81 \pm 4.65 \mathrm{SE}$, and $94.79 \pm 5.05 \mathrm{SE}$, respectively, for the three density groups $\left(\mathrm{F}_{2,39}=1.13 ; \mathrm{P}=0.33\right)$.

\section{Ant nests' effect on mango leaves and shoots}

During the harmattan season, the total number of leaves per shoot was higher $\left(\mathrm{F}_{1,390}=35.41, \mathrm{P}<0.0001\right)$ on nest shoots $(10.16 \pm 0.28 \mathrm{SE}$ leaves/shoot) than on control shoots $(8.05$ $\pm 0.22 \mathrm{SE}$ leaves/shoot). On the contrary, during the rainy season, there was no significant difference between control shoots $(8.22 \pm 0.14 \mathrm{SE}$ leaves/shoot $)$ and nest shoots $(8.55$ $\pm 0.16 \mathrm{SE})\left(\mathrm{F}_{1,576}=1.61, \mathrm{P}=0.21\right)$. In both seasons nest leaves were found to be smaller than other leaves. During the rainy seasons control leaves on nest shoots $\left(39.47 \pm 0.56 \mathrm{SE} \mathrm{cm}^{2}\right)$ and control shoots $\left(39.83 \pm 0.22 \mathrm{SE} \mathrm{cm}^{2}\right)$ were significantly $\left(\mathrm{F}_{2,4849}=238.78 ; \mathrm{P}<0.0001\right)$ larger than the leaves used for nest construction $\left(33.63 \pm 0.24 \mathrm{SE} \mathrm{cm}^{2}\right)$. The same trend was observed in the harmattan season $\left(\mathrm{F}_{2,3558}=120.66 ; \mathrm{P}<0.0001\right)$ with mean leaf sizes of $40.24 \pm 0.76 \mathrm{SE} \mathrm{cm}^{2}$ on control leaves on nest shoots, $41.20 \pm 0.41 \mathrm{SE} \mathrm{cm}^{2}$ on control shoots and $33.15 \pm 0.35 \mathrm{SE} \mathrm{cm}^{2}$ on nest leaves.

Withered leaves were more abundant on nest shoots compared to control shoots in both seasons (rainy season: $\chi^{2}=341.9 ; \mathrm{df}=1 ; \mathrm{P}<0.0001$ and harmattan season: $\chi^{2}=164.2$; $\mathrm{df}=1 ; \mathrm{P}<0.0001)$ as all the leaves on control shoots were green, while a mean of $13.58 \pm 1.31 \mathrm{SE} \%$ (rainy season) and $21.76 \pm 1.25 \mathrm{SE} \%$ (harmattan season) of the leaves on nest shoots were withered. Within nest shoots the majority of withered leaves were found among those leaves that were used for nests (rainy season: $\chi^{2}=181.59 ; \mathrm{df}=1 ; \mathrm{P}<0.0001$ and harmattan season: $\chi^{2}=122.02 ; \mathrm{df}=1 ; \mathrm{P}<0.0001$ ). Only $0.62 \pm 0.39 \mathrm{SE}$ and $6.12 \pm 1.34 \mathrm{SE} \%$ of the control leaves on nest shoots were yellow versus $23.64 \pm 2.03 \mathrm{SE}$ and $33.78 \pm$ $1.65 \mathrm{SE} \%$ of nest leaves on nest shoots in the rainy and in the harmattan seasons, respectively. Consequently, withering was exclusively associated with nest shoots, and on these shoots, leaves used for nests constructions were more affected.

Scale insects were found on nest leaves in high numbers, whereas they were almost absent outside ant nests. On nest shoots $7.81 \pm 1.76 \mathrm{SE}$ and $16.69 \pm 1.37 \mathrm{SE} \%$ of nest leaves were infected opposed to $3.52 \pm 1.55 \mathrm{SE}$ and $0.0 \%$ of the control leaves in rainy $\left(\chi^{2}=150.9 ; \mathrm{df}=1 ; \mathrm{P}<0.0001\right)$ and harmattan seasons $\left(\chi^{2}=\right.$ $10.2 ; \mathrm{df}=1 ; \mathrm{P}=0.0014)$, respectively. During both seasons, all the leaves on control shoots were without scale insects (rainy season: $\chi^{2}=311.2 ; \mathrm{df}=2 ; \mathrm{P}<0.0001$ and harmattan season: $\chi^{2}=37.6 ; \mathrm{df}=2$; $\mathrm{P}<0.0001$ ). Scale insects were not identified to the species level but were found to belong to Coccidae.

Leaf loss was also affected by nest building. More nest shoots (79 of 289 in rainy season and 26 of 196 in harmattan season) had lost at least one leaf, compared to the control shoots ( 25 of 289 in rainy season and 11 of 196 in harmattan season). Moreover, the average percentage of lost leaves per shoot was significantly different between the two types of shoot during the rainy $\left(\chi^{2}=33.14, \mathrm{df}=1, \mathrm{P}<0.0001\right)$ and the harmattan $\left(\chi^{2}=6.76, \mathrm{df}=1, \mathrm{P}=0.0093\right)$ season. A mean of 0.97 $\pm 0.21 \mathrm{SE} \%$ and $0.72 \pm 0.23 \mathrm{SE} \%$ of the leaves on control shoots were lost, while a mean of $3.01 \pm 0.37 \mathrm{SE} \%$ and $1.71 \pm$ $0.35 \mathrm{SE} \%$ of the leaves on nest shoots were lost, respectively, in rainy and harmattan season.

Table 2. Repeated measures statistics on the effect of time and Oecophylla ant density on the total number of leaves per tree. Seasonal mean values (per tree) are presented in Fig 1.

\begin{tabular}{ccccccc}
\hline \multirow{2}{*}{ Factors } & \multicolumn{2}{c}{$\begin{array}{c}\text { Total number of leaves per tree including leaves } \\
\text { used for nest construction }\end{array}$} & \multicolumn{2}{c}{$\begin{array}{c}\text { Total number of leaves per tree excluding } \\
\text { leaves used for nest construction }\end{array}$} \\
\cline { 2 - 7 } & $\mathrm{F}$ & $\mathrm{df}$ & $p$ & $\mathrm{~F}$ & $\mathrm{df}$ & $P$ \\
\hline $\begin{array}{c}\text { Trail density approach } \\
\text { Treatment }\end{array}$ & 1.26 & 2,57 & 0.29 & 1.38 & 2,57 & 0.26 \\
Time & 28.73 & 11,47 & $<0.0001$ & 28.81 & 11,47 & $<0.0001$ \\
Weeks*Treatment & 1.26 & 22,94 & 0.22 & 1.26 & 22,94 & 0.22 \\
Nest density approach & & & & & & \\
Treatment & 2.82 & 2,39 & 0.07 & 2.82 & 2,39 & 0.08 \\
Time & 16.15 & 11,29 & $<0.0001$ & 16.15 & 11,29 & $<0.0001$ \\
Weeks*Treatment & 0.98 & 22,58 & 0.50 & 0.98 & 22,58 & 0.50 \\
\hline
\end{tabular}




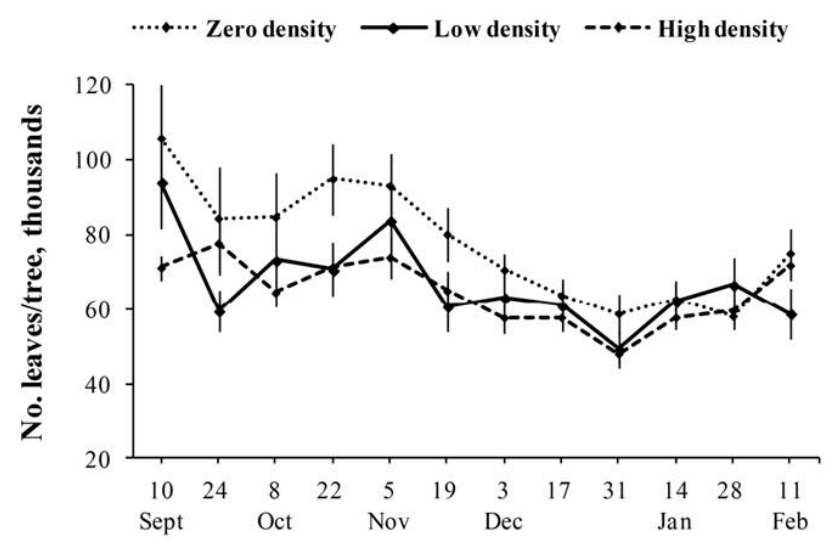

Sampling date

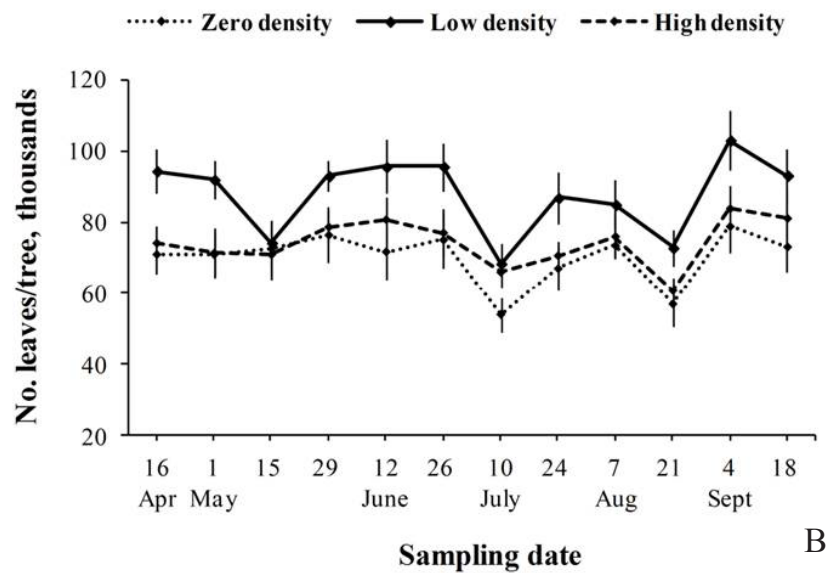

Fig 1. Mean number of mango leaves (excluding leaves used in ant nests) per tree by season on trees with different ant densities. A: ant trail density approach (September 2012 to February 2013); B: ant nest density approach (April to September 2013).

\section{Discussion}

Trees with weaver ants did not show significantly different number of leaves compared to control trees. This held true even if the leaves used in ant nests were considered "dead" to the tree and were subtracted from the total number of leaves. We can thus deduce from the current study that the foliar development and thus photosynthetic activities were unaffected by weaver ants. Several reasons could explain this. Firstly, the number of leaves used to form nests was low, $0.7 \%$ in average. Similarly, Offenberg et al. (2006) estimated that, $O$. smaragdina used as little as $0.25 \%$ of the leaves of the mangrove tree $R$. mucronata to form their nest. Thus, weaver ants in general use only few of the available leaves on trees to build their nests. Therefore, this potentially negative impact is limited and likely to be outweighed by the positive impacts of weaver ants. Secondly, the agro-physiological factor, bud initiation, can be brought up. In most cases, when the terminal bud was used for nest construction, it led to the formation of secondary buds on the shoot and thus the formation of new flushes (Anato, unpublished data). This observation may explain the higher average number of leaves per shoot on nest shoots compared to control shoots in the harmattan season. In the rainy season, however, rains led to extensive leaf flush which may have reduced the effect of bud initiation as there was no significant difference in the number of leaves on shoots between the two groups during this part of the year. In harmattan, the extra leaves on nest shoots may reduce the negative impact of nest building by increasing the leaf surface vacant for photosynthesis which may again affect fruit production positively. This is an important issue to be studied together with the direct effect of weaver ants in the future.

The smaller size of leaves used in nests probably derived from the ants' nesting behavior as they prefer to build their nests at the apical end of shoots where the young and still not fully grown leaves are situated. Similarly, Offenberg et al (2006) observed that $O$. smaragdina showed a strong preference for young leaves on $R$. mucronata in a Thai mangrove. On the other hand, there was no size difference between the control leaves on nest and control shoots, showing that the nests did not affect the size of neighboring leaves.

Weaver ants engage in trophobiotic interactions with honeydew producing hemipterans, including scale insects (Way, 1963; Hölldobler \& Wilson, 1990; Blüthgen \& Fiedler, 2002). This was also evident on mango in the present study as the presence of scale insects was strongly correlated with ant nests. Thus, mango leaves indirectly support the ants via the scale insects and in this way leaves loose nutrients. However, ant-hemipteran trophobioses have most often only low costs to the plants unless the involved hemipterans are vectors of plants diseases. The scale species attended by the ants in this study has not been identified by a specialist taxonomist, however, based on morphology and behavior we believe it to be Udinia catori (Green), which is also the main hemipteran species protected by weaver ants on mango trees in Benin (Germain et al., 2010; Vayssières, 2012). This species is a minor pest in Benin and is not known as a vector of viruses (Germain et al., 2010; Vayssières, 2012). Furthermore, a meta-analysis showed that plants in general benefit from anthemiptera interactions as the ants positive effects on plants (by deterring herbivores that are more detrimental than the hemipterans) more than outweigh the negative impact of a higher standing crop of sap-sucking hemipterans (Styrsky \& Eubanks 2007). Thus, counter intuitively, the presence of ant attended hemipterans may actually benefit host plant fitness. In the present study the increased presence of scale insects on ant trees did not seem to lead to any detrimental effects on leaf performance except, maybe, the increased incidence of withering and lost leaves on nest shoots. An increased incidence of withered leaves in the nests would be expected, though, as old leaves were weaved together with young leaves. This prevents the old leaves to fall to the ground when they wither. However, it cannot be ruled out that leaves also showed reduced longevity and thus earlier withering due to the physical stress of being bended out of position when used in an ant nests and by being associated with attended scale 
insects. The physical stress on leaves may also have been the reason for the observed increase in lost leaves on ant nest shoots. Our belief, though, is that these negative effects are small, as they did not affect the total number of leaves on trees, neither their dbh.

Regarding the dbh, though, it should be noted that these measurements were taken only once during the study and thus represent the growth of trees during their entire lifetime. As the plantation was colonized by weaver ants 10 years ago it is possible, e.g., that trees with abundant weaver ants during the study period may previously have had less or no weaver ants, as the ants may move between trees. Therefore, the lack of an ant density effect on the dbh recorded in the present study should be interpreted with caution. Further studies tracking tree growth under known ant densities are needed to elucidate this effect further. On the other hand, it has been shown by several authors that there is a strong correlation between stem volume and foliar biomass (Bartelink, 1997; Swenson \& Enquist, 2008), supporting that stem growth will be unaffected by ant density as long as leaf area is unaffected.

In the context of weaver ants as biological control agents it has been claimed that ant trail density scores above $50 \%$ are desirable in plantations. Above this level ant densities are sufficient to afford effective protection against pest insects (Peng \& Christian, 2004; 2005). In the present study, trail densities were considerably higher $(>80 \%)$ in the high density group, yet, without showing any sign of a detrimental effect on leaf performance on the trees. Thus, based on the present study, the high ant densities required for efficient biocontrol does not seem to conflict with leaf performance.

In conclusion, the seemingly detrimental effects of nest building by weaver ants are either not real costs to the plants (smaller leaves and withered leaves) or are of limited impact (lost leaves and scale infections). As a consequence they do not translate into reduced leaf performance on ant trees. In other words, farmers using weaver ants for biocontrol should not worry about the effect of nest building on their crop trees.

\section{Acknowledgements}

We would like to thank Mr Gaba Lawal for allowing us to do this research in his field. We are grateful to Pascal Ayelo and other local people for technical help and assistance in the field. The Danish International Development Assistance (DANIDA) financed and supported this research (Project: 'Increasing Value of African Mango and Cashew Production' no.: $10-025 \mathrm{AU})$.

\section{References}

Bartelink, H.H. (1997). Allometric relationships for biomass and leaf area of beech (Fagus sylvatica L). Annals of Forest Science, 54: $39-50$.

Blüthgen, N. \& Fiedler, K. (2002). Interactions between weaver ants Oecophylla smaragdina, homopterans, trees and lianas in an Australian rain forest canopy. Journal of Animal Ecology, 71: 793-801. doi: 10.1046/j.1365-2656.2002.00647.x

Buckley, R.C. (1987). Interactions involving plants, homoptera, and ants. Annual Review of Ecology and Systematics, 18:111135.

Crozier, R.H., Newey, P.S., Schlüns, E.A. \& Robson, S.K.A. (2010). A masterpiece of evolution - Oecophylla weaver ants (Hymenoptera: Formicidae). Myrmecological News, 13: 57-71.

Dagnelie, P. (2003). Principes d'expérimentation : planification des expériences et analyse de leurs résultats. http://www. dagnelie.be. (accessed date: 15 November, 2013).

Dillwith, J.W., Berberet, R.C., Bergman, D.K., Neese, P.A., Edward, R.M. \& Mcnew, R.W. (1991). Plant biochemistry and aphid populations: Studies on the spotted alfalfa aphid, Therioaphis maculata. Archives of Insect Biochemistry and Physiology, 17: 235-251.

Dwomoh, E.A., Afun, J.V.K., Ackonor, J.B. \& Agene, V.N. (2009). Investigations on Oecophylla longinoda (Latreille) (Hymenoptera: Formicidae) as bio control agents in the protection of cashew plantations. Pest Management Science, 65: 41-46. doi: 10.1002/ ps. 1642

Germain J.-F., Vayssieres, J.-F., \& Matile-Ferrero, D. (2010). Preliminary inventory of scale insects on mango trees in Benin. Entomologia Hellenica, 19: 124-131.

Hölldobler, B. \& Wilson E.O. (1990). The ants. Harvard University Press, Cambridge.

Hölldobler, B. (1983). Territorial behaviour in the green tree ant (Oecophylla smaragdina). Biotropica, 15: 241-250.

Korine, C., Kalko, E.K.V.\&Herre, E.A. (2000). Fruit characteristics and factors affecting fruit removal in a Panamanian community of strangler figs. Oecologia, 123: 560-568. doi: 10.1007/PL00008861

Lim, G.T., Kirton, L.G., Salom, S.M., Kok, L.T., Fell, R.D. \& Pfeiffer, D.G. (2008). Mahogany shoot borer control in Malaysia and prospects for biocontrol using weaver ants. Journal of Tropical Forest Science, 20: 147-155.

Offenberg, J. \& Wiwatwitaya, D. (2010). Sustainable weaver ant (Oecophylla smaragdina) farming: harvest yields and effects on worker ant density. Asian Myrmecology, 3: 55-62.

Offenberg, J. (2007). The distribution of weaver ant pheromones on host trees. Insectes Sociaux, 54: 248-250. doi:10.1007/ s00040-007-0938-5

Offenberg, J., Nielsen, M.G., Macintosh, D., Aksornkoae, S. \& Havanon, S. (2006). Weaver Ants Increase Premature Loss of Leaves Used for Nest Construction in Rhizophora Trees. Short communication. Biotropica, 38: 782-785. doi : 10.1111/j.1744-7429.2006.00206.x

Olotu, M.I., Du Plessis, H., Seguni, Z.S. \& Maniania, N.K. (2013). 
Efficacy of the African weaver ant Oecophylla longinoda (Hymenoptera: Formicidae) in the control of Helopeltis spp. (Hemiptera: Miridae) and Pseudotheraptus wayi (Hemiptera: Coreidae) in cashew crop in Tanzania. Pest Management Science, 69: 911-918. doi: $10.1002 /$ ps.3451.

Pandey SK, Singh H, 2011. A Simple, Cost-Effective Method for Leaf Area Estimation. Journal of Botany. Article ID 658240 doi:10.1155/2011/658240

Peng, R.K. \& Christian, K. (2004). The weaver ant, Oecophylla smaragdina (Hymenoptera: Formicidae), an effective biological control agent of the red-banded thrips, Selenothrips rubrocinctus (Thysanoptera: Thripidae) in mango crops in the Northern Territory of Australia. Intenational Journal of Pest Management, 50: 107-114. doi:10.1080/09670870410001658125

Peng, R.K. \& Christian, K. (2005). The control efficacy of the weaver ant, Oecophylla smaragdina (Hymenoptera: Formicidae), on the mango leafhopper, Idioscopus nitidulus (Hemiptera: Cicadellidea) in mango orchards in the Northern Territory. Intenational Journal of Pest Management, 51: 297-304. doi: 10.1080/09670870500151689

Riedell, W.E. \& Blackmer, T.M. (1999). Leaf reflectance spectra of cereal aphid-damaged wheat. Crop Science, 39: 1835-1840.

Sinzogan, A.A.C., Van Mele, P. \& Vayssières J-F. (2008). Implications of on-farm research for local knowledge related to fruit flies and the weaver ant Oecophylla longinoda in mango production. Intenational Journal of Pest Management, 54: 241246. doi:10.1080/09670870802014940

Styrsky, D.J. \& Eubanks, M.D. (2007). Ecological consequences of interactions between ants and honeydew-producing insects. Proceedings of the Royal Society B, 274: 151-164. doi: 10.1098/rspb.2006.3701

Swenson, N.G. \& Enquist, B.J. (2008). The relationship between stem and branch wood specific gravity and the ability of each measure to predict leaf area. American Journal of Botany, 95: 516-519. doi:10.3732/ajb.95.4.516

Tinkeu, L.N., Ladang, D., Vayssières, J-F. \& Lyannaz, J.P. (2010). Diversité des espèces de mouches des fruits (Diptera : Tephritidae) dans un verger mixte dans la localité de Malang (Ngaoundéré, Cameroun). International Journal of Biological and Chemical Sciences, 4: 1425-1434. doi: 10.4314/ijbcs.v4i5.65530
Van Mele, P. \& CUC, N.T.T. (2003). Ants as friends: Improving your tree crops with weaver ants. [WWW document]. URL http://www.antbase.net/pdf/ants_as_friends_english.pdf.

Van Mele, P. (2008). A historical review of research on the weaver ant Oecophylla in biological control. Agricultural and Forest Entomology, 10: 13-22. doi:10.1111/j.14619563.2007.00350.x

Van Mele, P., Cuc, N.T.T., Seguni, Z., Camara, K. \& Offenberg, J. (2009). Multiple sources of local knowledge: a global review of ways to reduce nuisance from the beneficial weaver ant Oecophylla. International Journal of Agricultural Resources, Governance and Ecology., 8: 484-504. doi: 10.1504/IJARGE.2009.032646

Van Mele, P., Vayssières, J-F., Van Tellingen, E. \& Vrolijks, J. (2007). Effects of an African weaver ant, Oecophylla longinoda, in controlling mango fruit flies (Diptera: Tephritidae) in Benin. Journal of Economic Entomology, 100: 695-701.

Vayssières, J.-F. (2012). Tri-trophic relations between different food web structures about fruit flies in tropical fruit agroecosystems. Habilitation à Diriger des Recherches. CIRAD-Hortsys. Université Paris Est, Paris, France, p. 158.

Vayssières, J.-F., Korie, S., Coulibaly, T., Temple, L. \& Boueyi, S. (2008). The mango tree in central and northern Benin: cultivar inventory, yield assessment, early infested stages of mangos and economic loss due to the fruit fly (Diptera: Tephritidae). Fruits, 63: 335-348. doi:10.1051/fruits:2008035

Way, M.J. \& Khoo, K.C. (1992). Role of ants in pest management. Annual Review of Entomology, 37: 479-503.

Way, M.J. (1954). Studies on the association of the ant Oecophylla longinoda (Latreille) (Formicidae) with the scale insect Saissetia zanzibarensis Williams (Coccidae). Bulletin of Entomological Research, 45: 113-134.

Way, M.J. (1963). Mutualism between ants and honeydew producing Homoptera. Annual Review of Entomology, 8: 307-344.

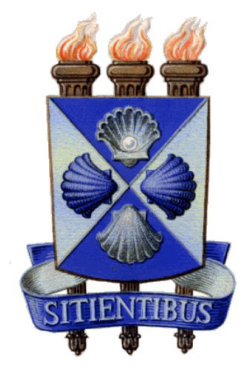

